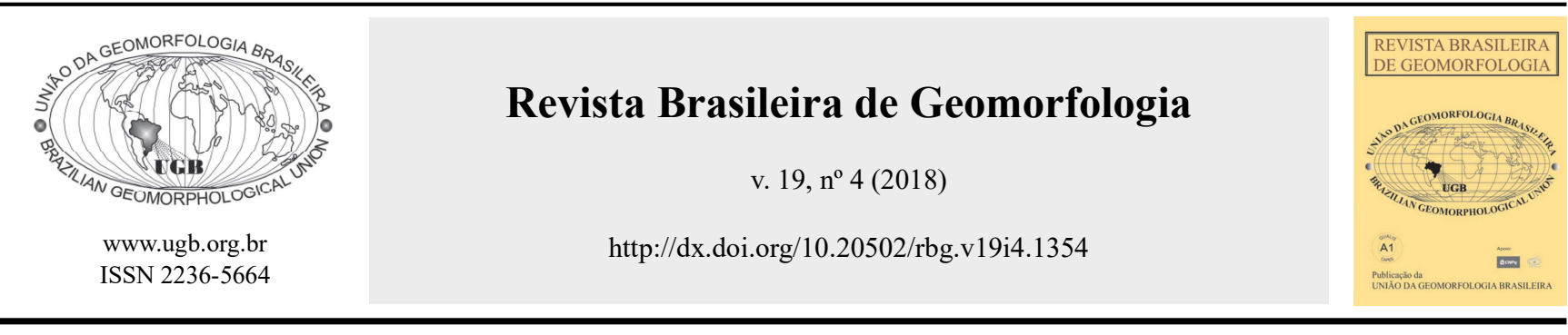

\title{
O PAPEL DOS PROCESSOS FLUVIAIS NA CONFIGURAÇÃO DE FUNDOS DE VALE NA BACIA DO RIO PARAÚNA - SERRA DO ESPINHAÇO MERIDIONAL, SUDESTE DO BRASIL
}

\section{THE ROLE OF THE FLUVIAL PROCESSES IN THE BOTTOM VALLEYS CONFIGURATION AT THE PARAÚNA RIVER BASIN - MERIDIONAL ESPINHAÇO RANGE, SOUTHEASTERN BRAZIL}

\author{
Alex de Carvalho \\ Instituto Federal de Minas Gerais \\ Rua Pandiá Calógeras, 898, Ouro Preto, Minas Gerais. CEP 35400-000. Brasil \\ E-mail: alex.carvalho@ifmg.edu.br \\ Antônio Pereira Magalhães Junior \\ Departamento de Geografia, Universidade Federal de Minas Gerais \\ Av. Antônio Carlos, 6.627, Belo Horizonte, Minas Gerais. CEP 31270-901. Brasil \\ E-mail: magalhaesufmg@yahoo.com.br \\ Bernardo Ribeiro Filizzola \\ Instituto de Geociências, Universidade Federal de Minas Gerais \\ Av. Antônio Carlos, 6.627, Belo Horizonte, Minas Gerais. CEP 31270-901. Brasil \\ E-mail:filizzola.bernardo@gmail.com
}

Cristiano Pena Magalhães Marques Instituto de Geociencias, Universidade Federal de Minas Gerais Av. Antônio Carlos, 6.627, Belo Horizonte, Minas Gerais. CEP 31270-901. Brasil

E-mail: cristianommarques@gmail.com

Informações sobre o Artigo

Recebido (Received):

17/11/2017

Aceito (Accepted):

10/07/2018

\section{Palavras-chave:}

Evolução de Fundos de Vale; Geomorfologia Fluvial; Luminescência Opticamente Estimulada (LOE); Serra do Espinhaço Meridional.

\section{Keywords:}

Evolution of the Bottom Valleys; Fluvial Geomorphology; Optically Stimulated Luminescence (OSL); Meridional Espinhaço Range.

\section{Resumo:}

Este trabalho investiga o papel dos eventos geomorfológicos fluviais na configuração do relevo da bacia do Rio Paraúna ao longo do Quaternário, enfocando a configuração dos fundos de vale. $\mathrm{Na}$ área investigada, os fundos de vale geralmente possuem dois ou três níveis deposicionais aluviais (planície de inundação - PI; e terraços - N1 e N2), sendo comum que as PI os N1 encontremse embutidos ou encaixados em relação aos níveis mais antigos e escalonados em relação aos níveis em contexto de vertente. O quadro geológico-geomorfológico e as características cronoestratigráficas dos depósitos, cuja datação foi realizada utilizando a metodologia da Luminescência Opticamente Estimulada (LOE), sugerem que, ao longo do Pleistoceno e de grande parte do Holoceno, os vales evoluíram em ciclos alternantes de sedimentação e encaixamento da drenagem. Contudo, o final do Holoceno tem sido marcado pela estabilização do nível de base regional representado pelo Rio Paraúna e pela alteração na dinâmica hidrossedimentar, que tem proporcionado a formação de planícies embutidas nos terraços. As idades dos depósitos obtidas com a datação por LOE permitem 
supor que as PI correspondem a um evento de sedimentação regional, associado à dinâmica fluvial atual. As PI possuem idades que variam $270( \pm 60)$ e $170( \pm 25)$ anos. Os N1 também parecem estar associados a um evento de sedimentação de escala regional, com uma dinâmica hidrossedimentar diferente da atual, cujas idades variam entre $1.480( \pm 250)$ e $590( \pm 110)$ anos. Os N2 apresentaram idades bastante divergentes. No Córrego da Sepultura, a idade obtida é de $26.350( \pm 4.470)$, tornando esse o N2 mais antigo da área investigada. Nos demais vales, as idades variaram entre $3.000( \pm 490)$ e $4.200( \pm 480)$ anos. Considerando esses dados, pode-se supor que a formação dos N2 ocorreu através da instalação de eventos de sedimentação de escala local, afetando cada vale em momentos distintos. Portanto, é possível propor que a evolução dos vales pode ser dividida em duas fases. A fase mais antiga, que compreende o final do Pleistoceno e o início do Holoceno, provavelmente foi marcada pela instabilidade neotectônica, expressa em uma dinâmica de blocos mais intensa, permitindo a instalação de eventos erosivo-deposicionais distintos em cada vale. A fase mais recente, representada pelos últimos 2.000 anos, deve ter sido marcada pela menor movimentação de blocos no interior da Serra do Espinhaço Meridional, o que pode ter permitido a estabilização do nível de base regional e a regularização de grande parte dos perfis longitudinais dos cursos fluviais.

\begin{abstract}
:
This paper investigates the role of fluvial geomorphologic events in the configuration of the Paraúna River basin landscape during the Quaternary, focusing the bottom valleys configuration. In the investigated area, the bottom valleys generally have two or three alluvial depositional levels (floodplain - PI; and terraces - N1 and N2), being common that the PI and N1 are found embedded in relation with the older levels and stepped in relation with the levels that are in downhill context. The geological-geomorphological scenario and the chronostratigraphic characteristics of the deposits, that were dated using the Optically Stimulated Luminescence (OSL) methodology, suggests that during the Pleistocene and a big part of the Holocene the valleys evolved in alternated cycles of sedimentation and drainage of incision. However, the Holocene final period has being marked by the stabilization of the regional base level represented by the Paraúna River and by the alteration of the hydrosedimentary dynamic, proportionating the formation of embedded plains in the terraces. The deposits ages acquired by OSL allow assuming that the PI corresponds to an event of regional sedimentation, associated with the current fluvial dynamic. The PI have ages that vary between $1.480( \pm 250)$ and $590( \pm 110)$ years. The N2 present very divergent ages. In the Sepultura Stream, the obtained age is $26.350( \pm 4.470)$, making this N2 the oldest in the investigated area. In the other valleys the ages vary from $3.000( \pm 490)$ to $4.200( \pm 480)$ years. Considering this data, it is possible to assume that the formation of the $\mathrm{N} 2$ occurred by the installation of sedimentation events in a local scale, affecting each valley in distinct moments. Therefore, it is possible to propose that the evolution of the valleys may be divided in two phases. The oldest phase, that comprehends the final of the Pleistocene and the beginning of the Holocene, probably was marked by neotectonic, expressed in a more intense dynamic of blocs, allowing the installation of distinct erosive-depositional events in each valley. The earliest phase, represented by the last 2.000 years, ought to be marked by a minor bloc's movement in the interior of the Meridional Espinhaço Range, what could have permitted the stabilization of the regional base level and the regularization of great part of the fluvial course's longitudinal profiles.
\end{abstract}

\section{Introdução}

Os cursos fluviais têm papel de destaque na morfogênese ao realizar os processos de erosão, transporte e sedimentação de partículas oriundas das formações superficiais (Perez-Filho et. al. 2006). A rede de drenagem constitui elemento geomorfológico com grande capacidade de refletir, direta ou indiretamente, as condições ambientais ou as suas alterações em uma bacia hidrográfica. Nesse sentido, as condições ambientais podem ser compreendidas como uma síntese das relações entre os fatores litológicos, estruturais, tectônicos, geomorfológicos, pedológicos e climáticos, além do uso e da cobertura do solo (Christofoletti, 1981).

Os depósitos sedimentares fluviais estão entre os principais registros da alteração da dinâmica 
fluvial, sinalizando as influências dos condicionantes geomorfológicos na evolução do relevo (Christofoletti, 1981). A estratigrafia dos registros deposicionais pode revelar aspectos relevantes da evolução fluvial, como o contexto e a dinâmica hidrossedimentar, as áreas fonte de sedimentos, a distância de transporte desde a desagregação nas vertentes até a deposição, bem como o tempo decorrido desde a deposição até o presente. Portanto, a análise estratigráfica pode subsidiar a reconstituição e a interpretação de eventos deposicionais, além de contribuir para a elucidação de aspectos importantes acerca da morfodinâmica ou de feições geomorfológicas específicas.

A Serra do Espinhaço Meridional é um dos principais domínios geológico-geomorfológicos cimeiros de Minas Gerais. É drenada, em extensa área, pela bacia hidrográfica do rio Paraúna. A literatura acadêmica demonstra, por outro lado, que os estudos geomorfológicos priorizam a unidade fisiográfica da Depressão de Gouveia - compartimento da Serra do Espinhaço Meridional drenado pelo ribeirão do Chiqueiro, um dos principais afluentes do rio Paraúna. São raros, portanto, os trabalhos que abordam, de maneira integrada, a geomorfologia fluvial nos vales dos principais afluentes do rio Paraúna, abrindo espaço para novos estudos que avancem na compreensão da relação entre a configuração geomorfológica e os sistemas fluviais na bacia. Entre os estudos mais abrangentes que foram realizados na região, estão os de King (1956), que trata da geomorfologia do Brasil Oriental, de Saadi (1991), com foco orientado sobre a morfotectônica de Minas Gerais, e de Valadão (2009), que discorre sobre a megageomorfologia do Brasil Oriental.

Saadi (1995) propõe uma série de eventos pleistocênicos, que teriam se sucedido na região da Depressão de Gouveia, destacando-se uma alternância de fases de dissecação fluvial, entulhamento dos vales, coluvionamento com afogamento e regularização da morfologia e fraca dissecação dos vales. No Holoceno, teria ocorrido uma reabertura completa dos vales, com o entalhe da calha, promovendo o recrudescimento dos processos erosivos nas vertentes, favorecendo os voçorocamentos. O Holoceno foi marcado pela formação de planícies de inundação e a continuidade do aprofundamento das calhas no assoalho rochoso. Segundo o autor, esses processos são resposta, em grande medida, a um cenário de certa instabilidade neotectônica presente ao longo de todo o Cenozoico. As evidências que embasam tal conclusão, ainda de acordo com Saadi (op. cit.), foram descritas por diversos autores como feições morfotectônicas presentes nas áreas marginais da Serra do Espinhaço Meridional e, principalmente, por observações diretas de falhamentos neotectônicos cortando depósitos pleisto-holocênicos. Portanto, é possível pressupor que a dinâmica fluvial cenozoica, a morfologia dos fundos de vale da Serra do Espinhaço Meridional, principalmente nas áreas deprimidas, e as fases e eventos erosivo-deposicionais resultem de um importante condicionamento neotectônico quaternário.

O objetivo principal deste artigo é investigar os eventos geomorfológicos fluviais na configuração do relevo da bacia do rio Paraúna ao longo do Quaternário, particularmente na configuração dos fundos de vale. As reflexões foram embasadas pelo estudo do quadro geológico-geomorfológico regional, bem como pelas características dos depósitos fluviais, incluindo a datação por Luminescência Opticamente Estimulada (LOE) em depósitos considerados chave. O trabalho busca favorecer, dessa forma, $\mathrm{o}$ aprofundamento do conhecimento sobre a influência dos condicionantes geológico-geomorfológicos na configuração atual dos fundos de vales fluviais na bacia do rio Paraúna e na dinâmica erosivo-deposicional quaternária dos principais vales da região.

\section{Área de estudo}

A área analisada compreende parte da Serra do Espinhaço Meridional, onde se localiza a bacia do rio Paraúna, afluente do rio das Velhas. Este compartimento integra a Cadeia do Espinhaço, um conjunto de terras elevadas que delimita a bacia hidrográfica do rio São Francisco, à oeste, e as bacias dos rios que desaguam no Oceano Atlântico, à leste (Figura, 1). De acordo com Valadão (2009), o escarpamento da Serra do Espinhaço delimita duas regiões com significativa diferenciação altimétrica, sendo que no interior continental se encontram superfícies mais elevadas e na fachada atlântica estão aquelas mais rebaixadas. Neste estudo, foram investigados os vales do rio Paraúna e de seus afluentes: córrego da Sepultura; e ribeirões Congonhas e do Chiqueiro.

A Serra do Espinhaço Meridional é considerada um orógeno colisional edificado no Mesoproterozóico (Almeida-Abreu e Renger, 2002). Esse conjunto de terras elevadas possui direção NNW-SSE, destacandose que o seu limite meridional é marcado pelo Cráton do São Francisco. No final do Neoproterozoico essa faixa 
orogênica foi reativada mantendo a compartimentação deixada durante a orogênese do Mesoproterozoico. Devido à sua morfologia, no território do estado de Minas Gerais, a Serra do Espinhaço Meridional pode ser considerada um planalto de direção geral N-S, cuja forma se assemelha a um bumerangue de convexidade orientada para oeste (Almeida-Abreu e Renger, 2002; Saadi, 1995). Ainda de acordo com Saadi (1995), o alinhamento N-S da serra é constituído por um conjunto de linhas de cristas descontínuas, sendo que na região de Diamantina encontra-se o planalto de aspecto maciço mais elevado, cuja altitude média é de 1.300 metros.

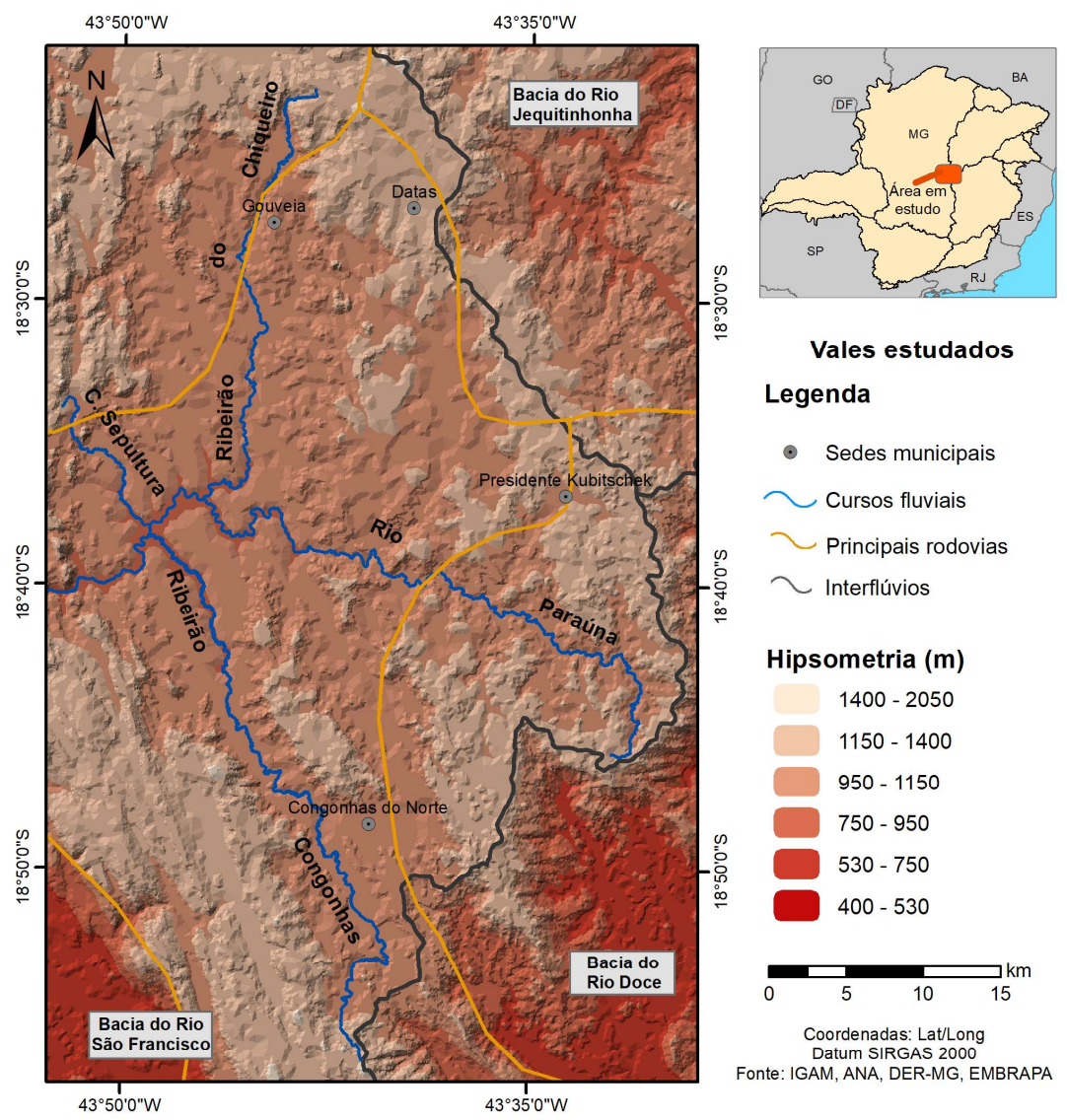

Figura 1 - Localização e hipsometria dos vales estudados.

Knauer e Grossi-Sad (1997) e Fogaça (1997) apresentaram as principais unidades litológicas da região, salientando que a evolução geomorfológica regional é controlada, em grande parte, pelas diferenças de comportamento dessas unidades em relação aos processos intempéricos e erosivos (Saadi, 1995). Na parte rebaixada, no interior da Serra do Espinhaço Meridional, afloram os granitoides, gnaisses e migmatitos do Complexo de Gouveia, de idade arqueana. As rochas graníticas possuem inclusões de rocha máfica e de migmatito. Também de idade arqueana são as rochas do Grupo Pedro Pereira, de ocorrência limitada e composto por xistos verdes, sericita-quartzo-xistos e itabiritos. Essas rochas encontram-se posicionadas no Complexo de Gouveia. De idade paleoproterozoica, o Grupo Costa Sena é composto essencialmente por quartzo-mica xistos e filitos, rochas que ocorrem bordejando o Complexo de Gouveia. O Supergrupo Espinhaço possui idade entre 1,75 e 1,80 Ga, constituído pelo Grupo Guinda, Formação Galho do Miguel e Grupo Conselheiro Mata. As rochas filíticas e quartzíticas do Grupo Guinda (Formação São João da Chapada e Formação Sopa-Brumadinho) são responsáveis pela sustentação da Serra do Espinhaço e modelam seu escarpamento (Knauer e Grossi-Sad, 1997). O Grupo Macaúbas, datado do Proterozoico Superior, representa uma estreita faixa entre o Supergrupo Espinhaço e o Grupo Bambuí, sendo constituído por quartzitos e filitos, com intercalações com metadimictito. As respectivas unidades litológicas têm como característica importante o recobrimento local por sedimentos aluviocoluvionares cenozoicos (Figura 2). 

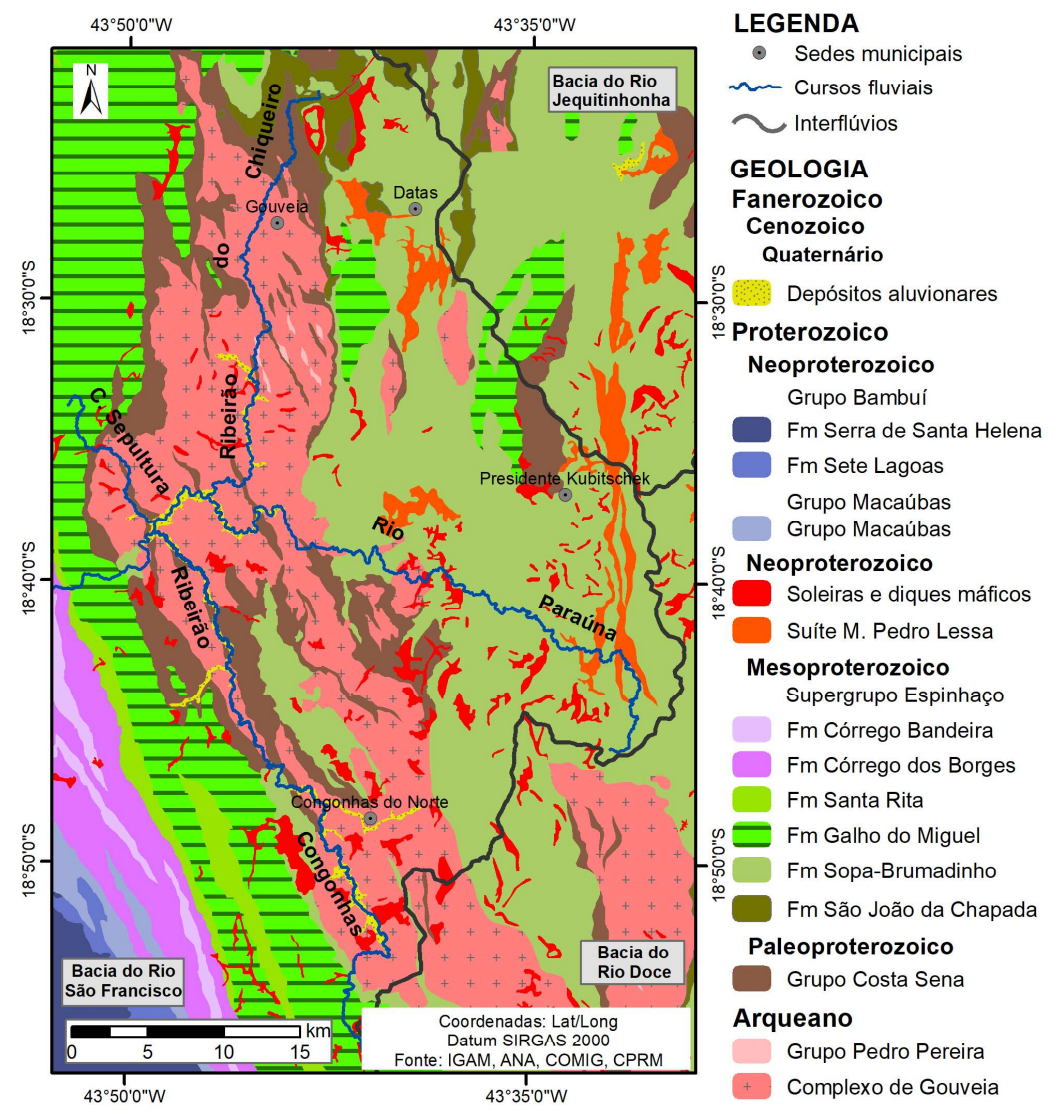

Figura 2 - Quadro geológico regional.

A estrutura da Serra do Espinhaço reflete a orogenia colisional neoproterozoica, sendo formada por um sistema de falhas inversas ou de empurrão/zonas de cisalhamento dúctil, resultando em dobras abertas e fechadas de eixo predominante norte-sul e vergência para oeste (Knauer, 2007). No contato entre o Cráton do São Francisco e a Serra do Espinhaço, Saadi (1995) identificou uma feição morfotectônica típica de front de cavalgamento, que separa o cráton do dobramento. Na borda leste, um conjunto de falhas com caráter e importância variáveis, compõem o cinturão de cavalgamentos na região próxima à zona proximal da colisão continental responsável pela edificação do Orógeno Espinhaço. Ainda segundo este autor, as cristas, as escarpas e os vales encaixados e adaptados às direções resultantes do tectonismo e às estruturas são resultantes da esculturação realizada pelos cursos de água. A dissecação do planalto foi responsável pela elaboração de áreas deprimidas, como a Depressão de Gouveia, nas quais rochas granitoides, metassedimentares e metavulcânicas sustentam outras formas de relevo, como as colinas policonvexas mais ou menos suavizadas.

\section{Procedimentos metodológicos}

Inicialmente, foram realizados o levantamento e a organização da base cartográfica digital, indicadas a seguir: Topografia (SRTM; ASTER; GEOMINAS - 1:50.000); Hidrografia; (IGAM, 2010 - 1:50.000); Litologia e Estruturas (COMIG, 2012 - 1:100.000; CPRM, 2014; - 1:100.000); Rodovias (DER - 1:10.000); Cartas Topográficas Digitais (IBGE, 1975 e 1979 - 1:100.000; 1:50.000); imagens Landsat (INPE). Complementarmente, foram utilizadas as imagens de satélite disponíveis no programa Google Earth ${ }^{\circledR}$. Para o reconhecimento da área de estudo, foram realizados trabalhos de campo preliminares, que subsidiaram a seleção dos vales fluviais do rio Paraúna e de alguns de seus afluentes que apresentaram indícios de condicionamento litoestrutural (padrão de drenagem diferente do esperado para o local, cotovelos, padrão retangular e outros). Desse modo, a análise dos perfis longitudinais e das configurações de fundo de vale contribuiu para a escolha dos afluentes a serem estudados. 
A partir da definição dos vales a serem estudados e da revisão bibliográfica, foram realizadas temporadas de trabalhos de campo a fim de identificar e caracterizar os níveis e sequências deposicionais presentes nos fundos de vale dos cursos fluviais principais das bacias investigadas. Buscou-se percorrer toda a extensão dos vales selecionados. Os níveis deposicionais fluviais foram identificados e caracterizados considerando variáveis como a tipologia dos níveis deposicionais (escalonado, embutido, encaixado), seu contexto espacial ao longo do vale (cota, desnível em relação à lâmina d'água do rio atual e distribuição), a espessura dos depósitos, composição granulométrica (verificada em campo, por meio do tato), organização das fácies sedimentares, tipo de contatos entre fácies, presença de estruturas primárias e outras. Os pontos de caracterização dos perfis foram georreferenciados e as informações foram espacializadas em cartas temáticas. Após a identificação dos níveis deposicionais foi realizada a representação de perfis estratigráficos síntese, abrangendo suas principais características. Os níveis deposicionais foram representados em sua organização longitudinal e transversal nos vales fluviais.

Entre os depósitos identificados e caracterizados, 13 foram selecionados para datação pelo método da LOE, via técnica SAR - single aliquot regeneration (Sallun e Suguio, 2006; Sallun et. al., 2007). A localização dos pontos selecionados para a coleta de sedimentos para a datação está representada na Figura 3. Essa escolha considerou a representatividade dos depósitos, a distribuição longitudinal ao longo dos vales, bem como a relação entre os depósitos em cada vale. A datação teve por objetivo a busca de informações que pudessem atender a perspectiva cronoestratigráfica do trabalho e, por conseguinte, a contextualização temporal dos eventos associados à origem dos níveis e das sequências sedimentares localizadas nos fundos de vale.

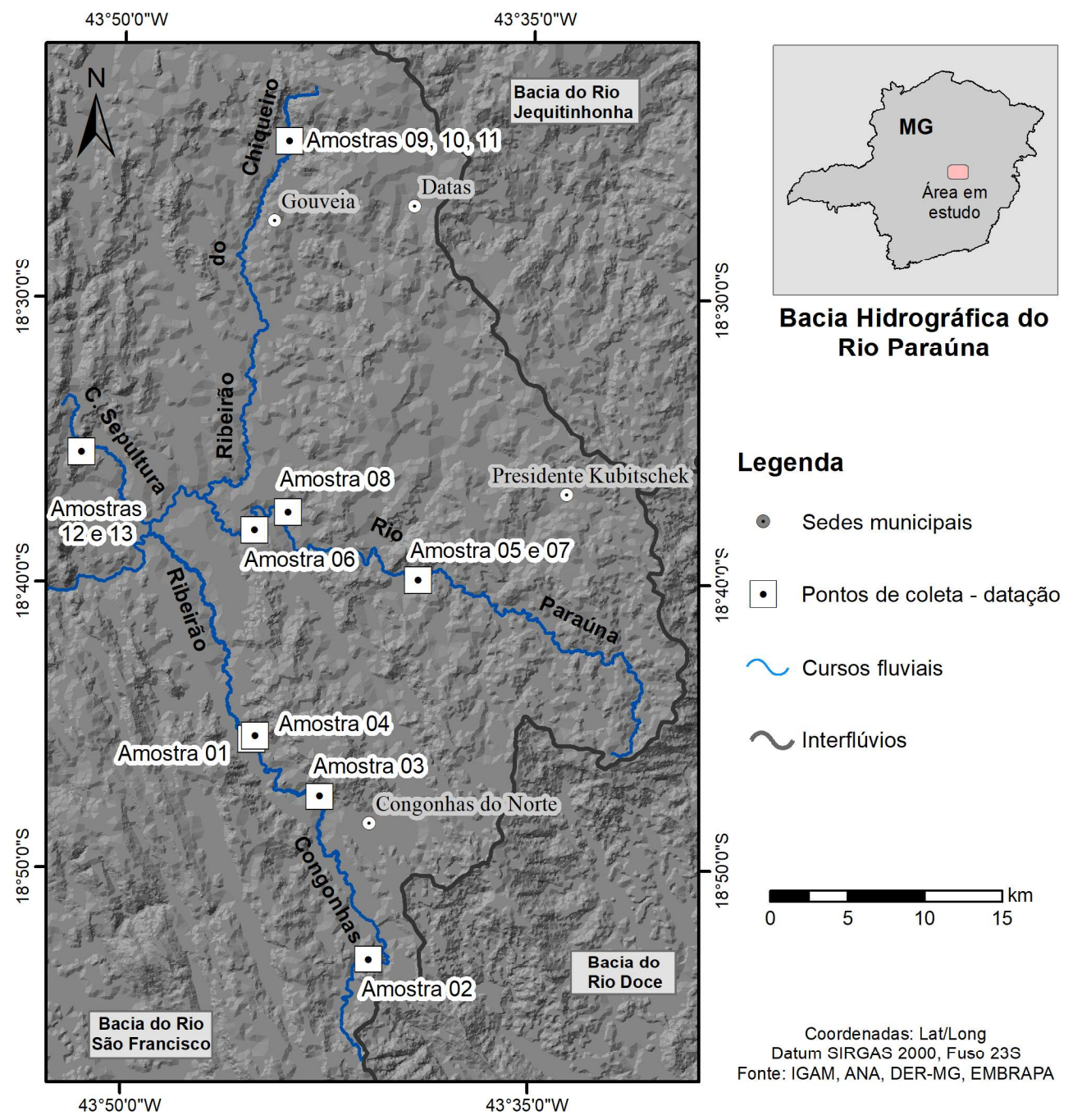

Figura 3 - Distribuição espacial dos pontos de coleta de amostras para datação via LOE. 
A datação por LOE mostra-se importante por possibilitar a determinação do tempo decorrido desde o último evento de sedimentação em que o grão de quartzo foi exposto à radiação solar. Ao entrar em contato com a radiação solar, o sinal de luminescência adquirido pelo grão de quartzo anteriormente é zerado e, ao se tornar protegido da luz solar pela sedimentação, tem início uma nova etapa de acumulação do sinal de luminescência, conforme descreve Correa et. al. (2008). Wallinga (2002) e Sallun e Suguio (2006) destacam que o sinal de luminescência apresenta como tendência o crescimento proporcional em relação à dose de radiação incidente, bem como com o tempo de irradiação. Isso permite o cálculo do período transcorrido desde a última vez que os elétrons foram liberados, o que é feito através de análises laboratoriais que consideram a luz emitida em resposta ao estímulo óptico disponibilizado. O protocolo SAR determina uma idade média entre 10 a 20 alíquotas. Assim, são elaboradas entre 10 e 20 curvas de calibração e são determinadas entre 10 e 20 idades. Como nesse protocolo apenas uma alíquota de aproximadamente $7 \mathrm{mg}$ é utilizada para a determinação de cada Paleodose, a alíquota usada na medida do sinal natural de LOE será a mesma utilizada nas outras etapas de irradiação para a construção da curva de calibração. A LOE possibilita a obtenção de idades que podem variar desde algumas dezenas de anos a até 1,5 Ma anos (Sallun e Suguio, 2006).

As amostras foram coletadas nas camadas basais dos depósitos fluviais, na maior profundidade em que havia material arenoso disponível, a fim de se identificar as idades iniciais da gênese dos depósitos. Utilizando tubos de PVC de $5 \mathrm{~mm}$ de diâmetro e 30 $\mathrm{cm}$ de comprimento realizou-se a coleta de sedimentos arenosos, atentando-se para a necessidade de proteger os tubos e os sedimentos da exposição à radiação solar. Os tubos previamente identificados foram inseridos, para cada amostra, de forma horizontal nos depósitos, por percussão, com o auxílio de uma marreta de borracha. Os procedimentos realizados estão de acordo com aqueles apresentados detalhadamente por Sallun et. al. (2007). Em seguida, as amostras foram destinadas ao Laboratório Datação, Comércio e Prestação de Serviços Ltda. ${ }^{1}$ (LVD), em São Paulo, que procedeu com a preparação e a análise, seguindo o protocolo LOE/SAR.

Os dados obtidos coma identificação, caracterização, mapeamento e datação dos níveis deposicionais aluviais foram interpretados a partir da elaboração de mapas que sobrepõem as informações de campo, a litologia e as estruturas. A interpretação integrada dessas informações, bem como daquelas disponíveis em outros trabalhos, subsidiou a identificação de possíveis controles litológicos, estruturais ou neotectônicos na área.

\section{Resultados e discussões}

\section{Níveis e sequências deposicionais de fundos de vale}

Os canais do rio Paraúna e de seus afluentes, ribeirão do Chiqueiro e córrego da Sepultura, apresentam padrões predominantemente sinuosos que, em alguns trechos, chegam a ser retilíneos. Raramente são encontrados trechos que podem ser classificados como meandrantes. Os trechos mais retilíneos estão associados principalmente aos quartzitos do Supergrupo Espinhaço, onde o controle litoestrutural é marcante. Nos baixos cursos desses canais, próximos à confluência com o rio Paraúna, e, sobretudo, nas litologias do Complexo de Gouveia, os canais possuem maior sinuosidade. A relativa menor energia dessas áreas e a própria influência das litologias granito-gnáissicas favorecem o aumento da sinuosidade dos canais. Entre os afluentes do rio Paraúna, apenas o ribeirão Congonhas pode ser classificado como de padrão meandrante, haja vista que seu vale aberto se estende desde parte do alto curso até a confluência com o rio Paraúna. Além disso, é possível identificar localmente feições deprimidas localizadas nas superfícies adjacentes ao canal, típicas de meandros abandonados. De modo geral, nas proximidades da confluência com o rio Paraúna e no médio/baixo curso deste, os vales tendem a ser mais abertos, denotando maior desenvolvimento dos fundos de vale. Nos trechos de médio e alto curso do rio Paraúna, do ribeirão do Chiqueiro e do córrego da Sepultura, os vales são relativamente mais estreitos, com características de vale em "V", o que deve estar associado ao recente encaixamento da rede de drenagem no substrato rochoso.

Nos vales investigados, ora foram identificados dois níveis deposicionais (planície e terraço) em contexto de fundo de vale, ora três níveis (uma planície e dois terraços). As planícies de inundação (PI) são feições deposicionais associadas à dinâmica fluvial atual. Os terraços (N1, N2 e N3) são feições de origem fluvial associadas à dinâmica pretérita, mas que por vezes são erodidos e desmontados pela dinâmica fluvial atual. Os níveis deposicionais escalonados tiveram sua origem e abandono seguidos por um significativo encaixamento do canal, sendo possível observar o contato entre a base

\footnotetext{
${ }^{1}$ Laboratório Datação, Comércio e Prestação de Serviços Ltda. - CNPJ: 05.403.307/0001-57.
} 
do depósito e o elúvio. Os níveis embutidos são aqueles em que a mudança da dinâmica hidrossedimentar foi responsável pela formação de um novo depósito sem que houvesse a incisão do canal. Assim, entre o talude que separa o nível embutido daquele imediatamente mais antigo há somente material aluvial pertencente ao depósito mais antigo. Os níveis encaixados podem ser considerados como transicionais entre os dois últimos citados, verificando-se uma pequena incisão da drenagem e um embutimento parcial do depósito mais novo naquele imediatamente mais antigo (Christofoletti, 1981).

A descrição pormenorizada dos perfis de PI, N1 e N2 e a distribuição transversal dos registros estão representadas nas Figuras 4 (Ribeirão do Chiqueiro e Córrego da Sepultura) e 5 (Ribeirão Congonhas e Rio Paraúna), o que possibilita comparar as características dos níveis deposicionais de diferentes vales. Os registros do $\mathrm{N} 3$ ou de outros níveis mais antigos se encontram em contexto de encosta, fugindo do foco desse trabalho, que investiga detalhadamente aqueles registros localizados em fundo de vale. A partir da observação das figuras, é possível verificar a semelhança entre as características das fácies, bem como a distribuição transversal dos níveis deposicionais em vales distintos. Verificouse a existência de dois padrões quanto aos níveis deposicionais em contexto de fundo de vale, sendo que ora o N2 representa o depósito mais antigo (Figura 4), ora o N1 ocupa essa posição (Figura 5). Em alguns vales a PI está embutida no N1 e este embutido ou levemente encaixado em relação ao N2. Outros vales apresentam PI embutida no N1, o qual se encontra escalonado em relação ao N2. As PI variam quanto ao estágio de evolução, sendo que em alguns trechos elas apresentam feições erosivas, indicando seu retrabalhamento ou desmanche, e, em outros, apresentam-se com aspecto consolidado, cuja espessura varia entre 1 e 3 metros. Via de regra, o N1 é representado por depósitos cuja espessura varia entre 2 e 3 metros, enquanto o N2 alcança até 5 metros de espessura. As PI e os N2 em fundo de vale geralmente não possuem fácies de seixos. Já os $\mathrm{N} 1$ e os $\mathrm{N} 2$ em contexto de vertente são comumente compostos por fácies basal de seixos. Em todos os vales investigados, a PI, o N1 e o N2 em fundo de vale têm a sua base na cota média da lâmina d'água, ora ligeiramente acima ou abaixo desta. Esses três níveis conservam as suas características topográficas originais.

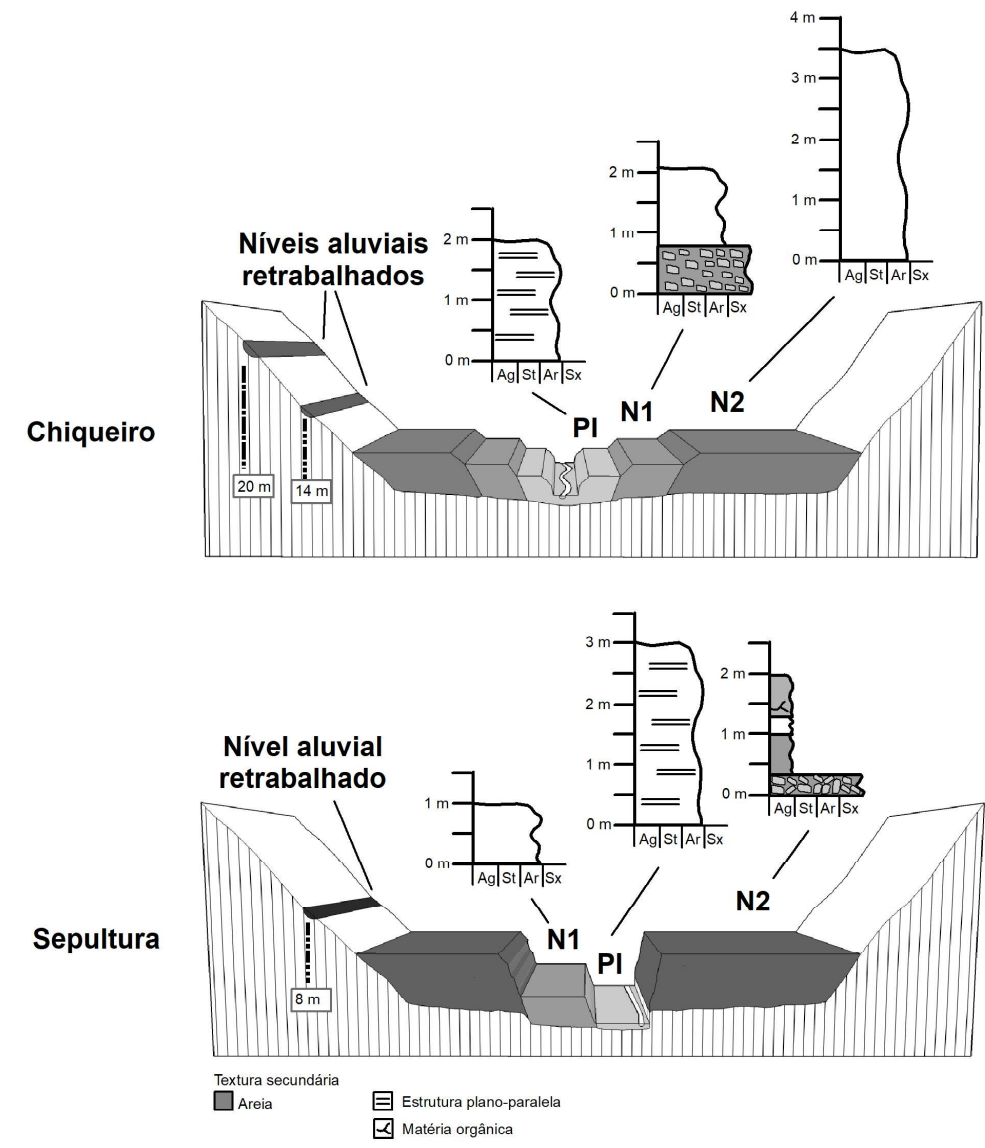

Figura 4 - Perfis transversais ao vale com a distribuição e síntese dos níveis deposicionais de fundo de vale (PI, N1 e N2) no Ribeirão do Chiqueiro e Córrego da Sepultura. 


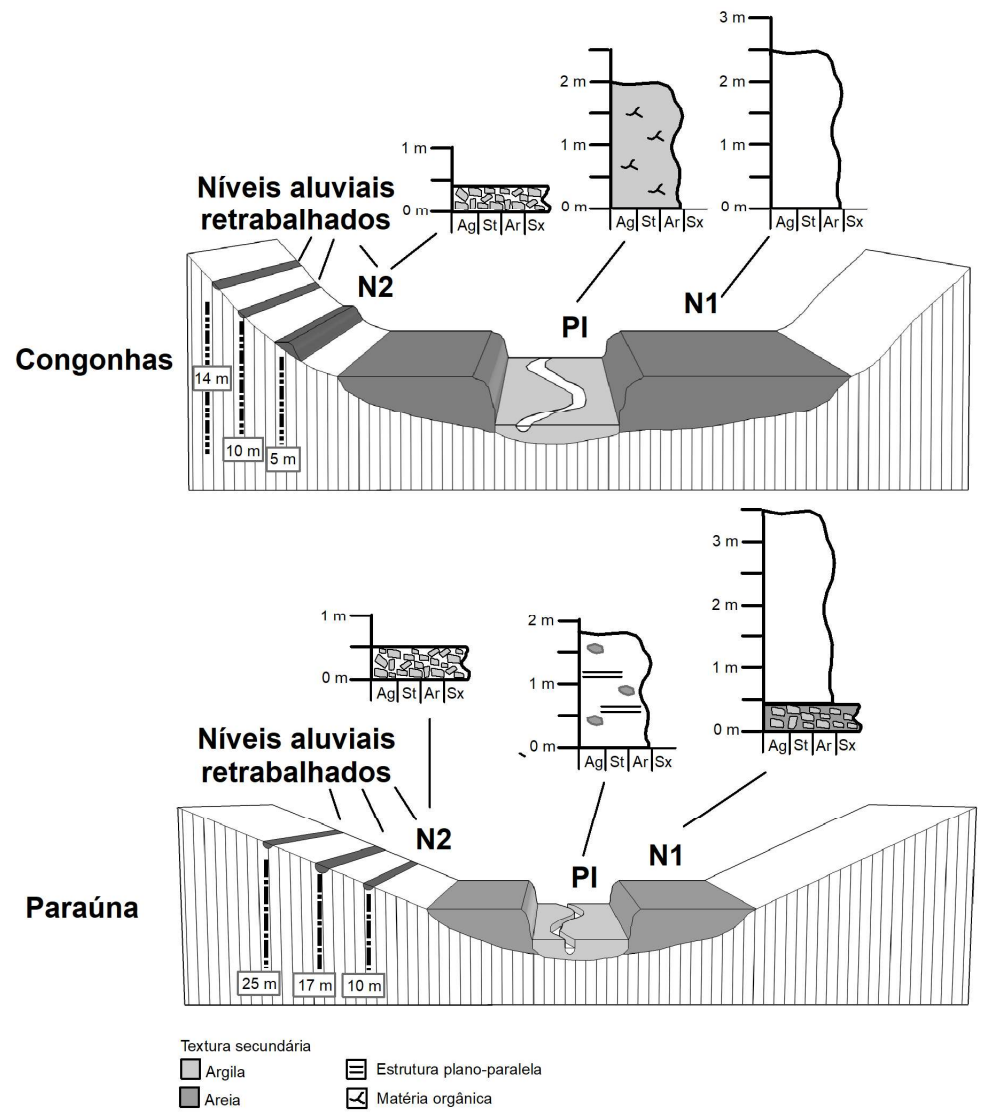

Figura 5 - Perfis transversais ao vale com a distribuição e síntese dos níveis deposicionais de fundo de vale (PI, N1 e N2) no Ribeirão Congonhas e no Rio Paraúna.

Em todos os vales foram encontrados níveis deposicionais em contexto de vertente, os quais não conservam as suas características topográficas originais, sendo possível observar indícios da ação de processos de vertente. É comum que o terraço mais antigo no fundo de vale, geralmente o N2, encontre-se escalonado em relação ao N3. Independentemente do número de níveis deposicionais em contexto de vertente, em cada vale, eles sempre estão escalonados em relação ao nível imediatamente mais antigo. São níveis com indícios de mobilização e cuja fácies conservada na vertente é composta predominantemente por seixos. Na bacia do ribeirão do Chiqueiro é comum a sobreposição de material coluvionar sobre a fácies de seixos (Ferreira, 2002), o que também pode ser encontrado em outros vales. Conforme Cruz (2006), enquanto a alta e algumas porções da média vertente da bacia do ribeirão do Chiqueiro são ocupadas por uma unidade coluvial de coloração vermelha, outras partes da média e a baixa vertente são ocupadas por outra unidade coluvial, de coloração amarela. A gênese de ambas unidades teria ocorrido no Pleistoceno Superior (Saadi, 1995).

\section{Descrição do perfil-síntese dos depósitos do N2}

O N2 apresenta variação em termos de posicionamento nos vales investigados. Nesse sentido, ele se encontra em contexto de fundo de vale associado aos cursos do ribeirão do Chiqueiro e do córrego da Sepultura, enquanto se encontra em contexto de vertente nos vales do ribeirão Congonhas e do rio Paraúna (Figura 6). No ribeirão do Chiqueiro, o N2 tem a sua base na cota média da lâmina d'água, ora sendo possível visualizar sua base, ora não sendo possível essa observação. No vale do córrego da Sepultura, a base do depósito se encontra à uma altura média de 3 metros em relação à lâmina d'água, o que denota o leve encaixamento ou o parcial embutimento do N1, nesse vale, em relação ao N2. Nesses dois vales, esses depósitos costumam ser lateralmente mais extensos e pareados, tornando-se mais amplos na medida em que se aproxima da confluência com o rio Paraúna. Nos vales do ribeirão Congonhas e do rio Paraúna esses níveis possuem cota altimétrica variável em relação à altura da lâmina d'água atual, fato que explica o 
encaixamento do $\mathrm{N} 1$ em relação ao N2. Em todos os vales, os depósitos $\mathrm{N} 2$ encontram-se escalonados em relação aos níveis deposicionais mais antigos. A seguir serão apresentadas as caracterizações sintéticas do N2 para os perfis situados em fundo de vale e também em contexto de vertente.
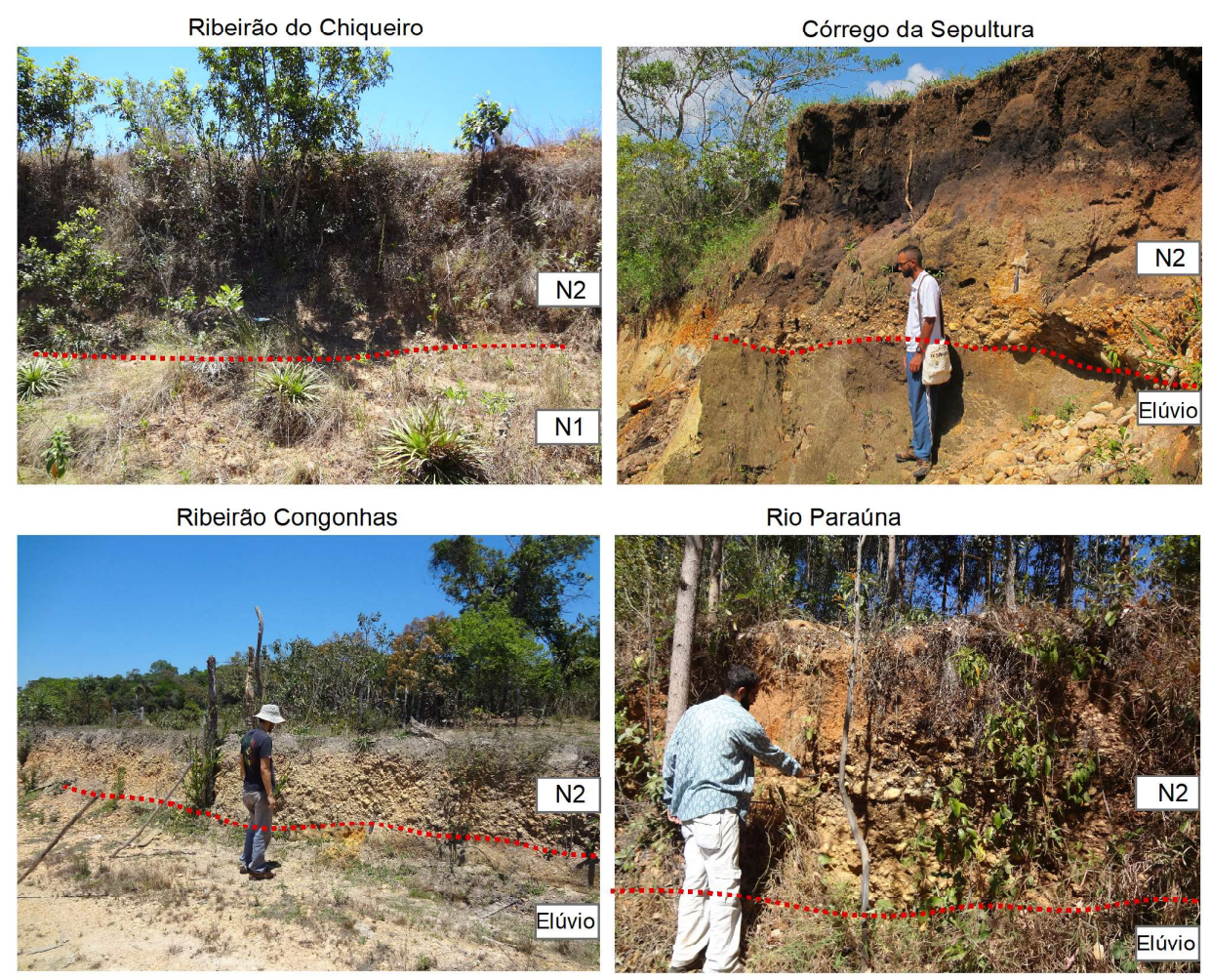

Figura 6 - N2 identificados nos vales estudados (a linha vermelha marca o contato inferior do depósito).

No vale do ribeirão do Chiqueiro, o N2 apresentase como um depósito composto por fácies única e predominantemente composta de areia, cuja espessura varia entre 2,5 e 3,5 metros, com aspecto homogêneo e maciço. Em alguns perfis foi possível observar a presença de uma fácies superior composta por seixos de quartzo, autossuportados, mal selecionados e arredondados a subarredondados. Via de regra, a parte inferior desses depósitos é encoberta pelo N1. No entanto, em alguns pontos onde o curso fluvial erodiu os depósitos da PI e do N1 é possível observar o limite inferior do N2. Em praticamente toda a extensão do vale do córrego da Sepultura, o N2 apresenta uma fácies basal composta por seixos predominantemente de quartzo, arredondados a subarredondados, autossuportados, com cerca de 30 $\mathrm{cm}$ de espessura, depositados sobre elúvio. Sobreposto a essa fácies de seixos se encontra uma sequência com três fácies com as seguintes características: sobreposta à camada de seixos, uma fácies argilo-arenosa, de aspecto maciço e bastante homogênea, com cerca de 70 $\mathrm{cm}$ de espessura; uma fácies argilosa com cerca de 30 cm de espessura; e uma fácies superior argilo-arenosa, com aproximadamente $70 \mathrm{~cm}$, cuja parte inferior é enriquecida em matéria orgânica, o que confere à essa fácies uma coloração mais escura na parte inferior e um pouco mais clara na parte superior.

Quanto aos níveis N2 situados em contexto de vertente nos vales do ribeirão Congonhas e do rio Paraúna, tratam-se de depósitos cuja morfologia foi alterada pela dinâmica de vertente. Nesses casos, as fácies compostas por seixos representam os elementos mais seguros para subsidiar as interpretações geomorfológicas, justamente devido ao nível de alteração, ou até mesmo ausência, das fácies superiores. De modo geral, os perfis apresentam fácies basal de seixos depositada sobre elúvio, composta por clastos arredondados a subarredondados, geralmente mal selecionados, cujo tamanho varia entre 2 e $15 \mathrm{~cm}$, com presença predominante de quartzo e outras litologias associadas, como quartzito e rochas básicas. No vale do ribeirão Congonhas, a base do N2 está a cerca de 5 metros de distância vertical da lâmina d'água e no vale do rio Paraúna essa distância é, em média, de 10 metros. 


\section{Descrição do perfil síntese dos depósitos do N1}

Os depósitos do N1 são de ocorrência regional, sempre ocupando o fundo de vale, com a sua base sendo encontrada abaixo do nível médio da lâmina d'água ou alguns centímetros acima (Figura 7). Trata-se de depósitos pareados e geralmente restritos lateralmente. Em todos os vales é mais comum que os depósitos de N1 sejam mais estreitos em trechos à montante e mais amplos em trechos à jusante. Nos fundos de vale em que se observa a presença de $\mathrm{N} 1$ e N2, o primeiro geralmente se encontra embutido em relação ao último. No entanto, em alguns trechos, como o médio e baixo curso do córrego da Sepultura, o N1 se encontra levemente encaixado em relação ao N2, embora isso só possa ser observado em áreas erodidas pelo curso fluvial. É bastante comum que predominem depósitos compostos por fácies arenosas ou areno-argilosas, de aspecto maciço e cuja espessura costuma variar entre 1,85 e 3,1 metros. Em alguns trechos é possível identificar uma fácies basal de seixos mal selecionados e suportados por matriz arenosa. Também são escassos os perfis em que são observadas estruturas sedimentares, sendo raras as estruturas plano-paralelas.
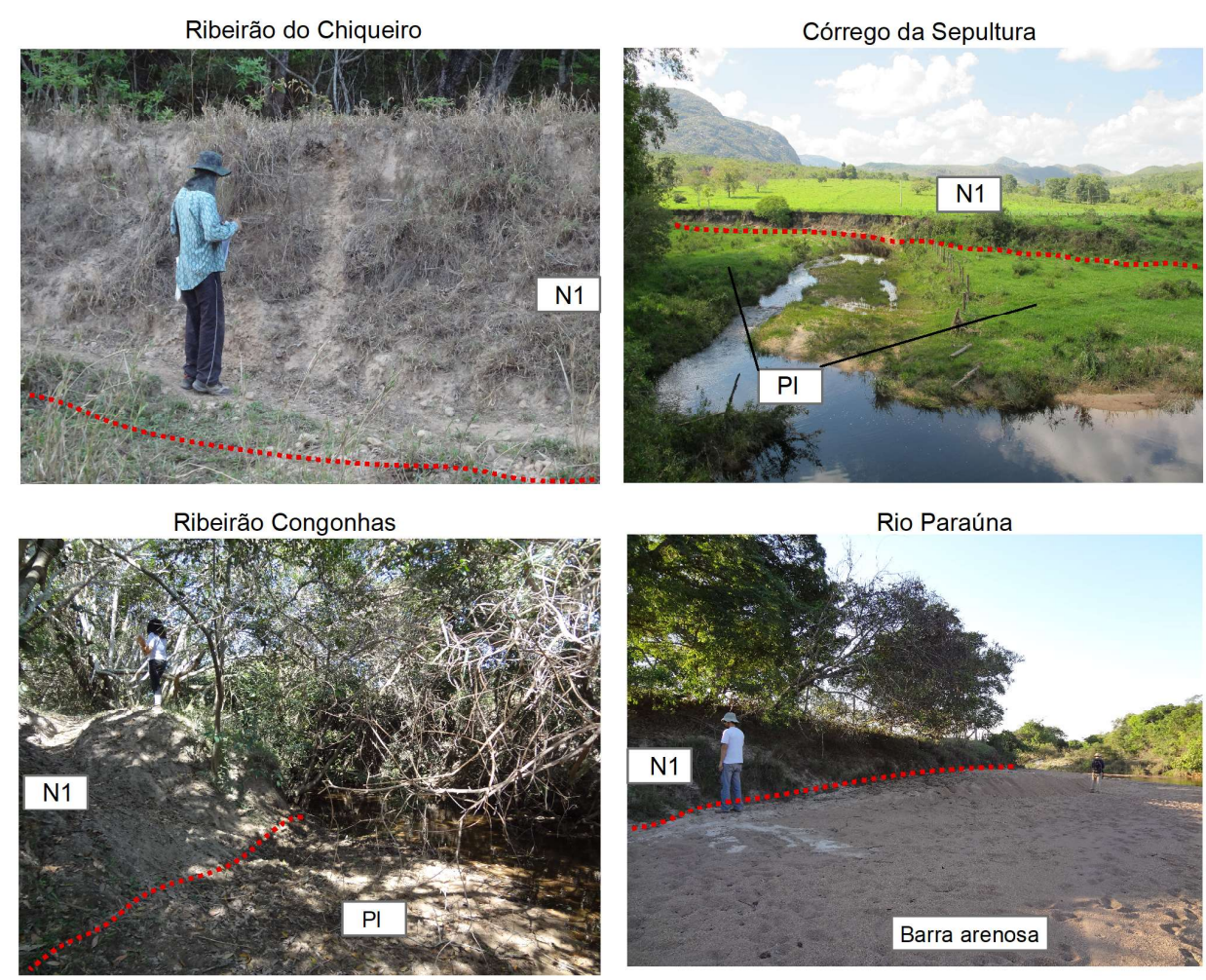

Figura 7 - N1 identificados nos vales estudados (a linha vermelha marca o contato inferior do depósito).

\section{Descrição do perfil-síntese dos depósitos de planície (PI)}

Nos vales investigados, as PI são pareadas e estão embutidas ou encaixadas nos terraços (comumente não há exposição dos contatos). São depósitos geralmente formados por um espesso pacote que representa uma fácies que varia de areno-argilosa a arenosa. Essa camada tem como padrão a homogeneidade e o aspecto maciço. Na maior parte dos vales, a espessura dos depósitos varia entre 1 e 2 metros, sendo que no vale do córrego da Sepultura trata-se de um depósito inconsolidado, sempre inferior a 1 metro. São registros lateralmente restritos e não são identificados em toda a extensão dos vales. Raramente é possível identificar a base desses depósitos, sendo, portanto, difícil precisar se há uma fácies basal de seixos em profundidade. No entanto, em alguns trechos de médio e alto curso, quando é possível observar o contato da parte inferior com o elúvio, não se verifica a presença de seixos. Destaca-se que em alguns trechos do vale do rio Paraúna, a planície possui grânulos de quartzo esparsos, com comprimento máximo de $2 \mathrm{~cm}$.

No vale do ribeirão Congonhas, a planície tem composição predominantemente areno-argilosa, diferenciando-se de outras planícies pela coloração 
escura decorrente do elevado teor de matéria orgânica. Os estudos de Benites et. al. (2007; 2003), de Horák et. al. (2011) e de Silva et. al. (2008) sugerem que a acumulação de matéria orgânica nas zonas deprimidas das planícies de inundação e de terraços em contexto de fundo de vale se devem à saturação hídrica, à elevada acidez, entre outras condições que favorecem o acúmulo de matéria orgânica e a formação de Organossolos. É possível identificar a presença de turfeiras, bastante comuns na Serra do Espinhaço. Também é possível associar a presença de solos e sedimentos ricos em matéria orgânica à acumulação sucessiva de material orgânico provenientes de plantas. Segundo Pontevedra-Pombal e Martinez Cortizas (2004), a umidade excessiva, o baixo pH e níveis de nutrientes e as temperaturas amenas devem ser responsáveis pela inibição da atividade microbiana, que realiza a decomposição da matéria orgânica. Além disso, a matéria orgânica é humificada e, de modo mais lento, mineralizada, gerando compostos de estruturas complexas. Esses compostos são constantemente enriquecidos de carbono fixo (Pereira et. al., 2005).

\section{Datação de sedimentos por LOE - via SAR}

A Figura 8 apresenta os resultados da datação de sedimentos fluviais via LOE - protocolo SAR. As amostras 01, 05 e 06 são representativas das planícies de inundação, indicando um período de formação recente. As idades desses depósitos variam entre $170( \pm 25)$ e 270 $( \pm 60)$ anos, indicando o início de um evento regional de formação de planícies em diferentes vales, sem o encaixamento da rede de drenagem nos segmentos próximos aos pontos de coleta, ou cujo encaixamento foi inferior a 1 metro. Deve-se frisar que as planícies, mesmo em trechos nos quais não houve coleta de amostras para a datação, são morfologicamente muito semelhantes, destacando-se o embutimento ou leve encaixamento em relação ao N1, além do predomínio de pacotes homogêneos ricos em sedimentos arenosos. Em diversos segmentos fluviais estudados, observa-se a presença de uma carga de leito que não condiz com a capacidade e competência esperada para a dinâmica atual dos respectivos cursos d'água. Em vários casos, os canais estão pavimentados por seixos e matacões que podem dificultar a incisão dos canais, proporcionando $\mathrm{o}$ encouraçamento das calhas. Devido à proximidade dos depósitos de N1 e N2 (em contexto de fundo de vale) em relação aos cursos fluviais, é possível supor que os seixos que promovem o encouraçamento das calhas em diversos segmentos podem ser resultantes do desmonte desses depósitos e de uma remobilização lenta dos clastos, devido à aparente pouca capacidade e competência dos cursos fluviais, como apontado por Bueno et. al. (1997). Uma possível explicação para a alteração da dinâmica hidrossedimentar pode estar associada às atividades antrópicas na região, destacando-se a pecuária e a mineração empreendidas a partir do século XVIII.

As amostras 02, 07, 09 e 12 indicam a fase inicial de formação do N1. Como se observa na Figura 8, trata-se de depósitos com idades que variam entre 590 ( \pm 110$)$ anos no ribeirão Congonhas a $930( \pm 100)$, no rio Paraúna. No caso do ribeirão do Chiqueiro, esse depósito apresentou idade de $1.480( \pm 250)$, um pouco superior à das demais amostras. Considerando as idades desses depósitos, incluindo a amostra 09, bem como as características dos depósitos N1, pode-se inferir que também se tratou de um evento de sedimentação regional, o qual, via de regra, não foi precedido ou sucedido por uma fase de rebaixamento do nível de base. Tem-se, dessa forma, um conjunto de depósitos $\mathrm{N} 1$ embutidos ou ligeiramente encaixados em relação aos depósitos N2.

As amostras 08, 10 e 13, referentes ao N2 são as que apresentam maiores discrepâncias. No vale do ribeirão do Chiqueiro, o depósito tem $3.000( \pm 490)$ anos, no vale do rio Paraúna $4.200( \pm 480)$ anos e no vale do córrego da Sepultura, a idade é de 26.350 $( \pm 4.470)$ anos. Nesses vales, cada depósito apresenta características morfológicas distintas. No ribeirão do Chiqueiro, o depósito está em contexto de fundo de vale, com o N1 embutido. Nessas condições, não há indícios de encaixamento nos últimos $3.000( \pm 490)$ anos, fortalecendo a hipótese de que uma alteração na dinâmica hidrossedimentar teria resultado na mobilização de parte desse depósito, permitindo a formação de níveis embutidos mais jovens. No córrego da Sepultura, o N2 está posicionado sobre elúvio e sua base se encontra 3 metros acima da lâmina d'água, enquanto no rio Paraúna essa distância vertical é de 10 metros. Embora não tenha sido realizada a datação dos depósitos N2 do ribeirão Congonhas, este nível está posicionado 5 metros acima da lamina d'água. A diferença de idades entre os depósitos do córrego da 
Sepultura e do rio Paraúna pode representar um indício da ocorrência de eventos de sedimentação distintos, com controles locais, os quais podem ser relacionados a movimentações diferenciais de blocos, dentro de uma dinâmica neotectônica regional. No caso do córrego da Sepultura, tendo em vista que o início da formação de seu N2 é de cerca de 26.350 anos, pode-se propor que as condições hidrossedimentares de sua bacia hidrográfica possibilitaram o desenvolvimento de uma dinâmica fluvial anterior à formação do N1 distinta do que se observava nos demais vales. Apesar da disparidade da idade encontrada para a amostra do N2 do córrego da Sepultura, quando comparada às idades do $\mathrm{N} 2$ em outros vales, existe subsídio na literatura que permite considerar seriamente o valor de 26.520 anos. Nesse sentido, Turcq et. al. (1987), após datar o mesmo depósito utilizando a técnica de radiocarbono, apontou uma idade de 31.950 anos. Considerando a idade máxima de incerteza do N2 (amostra 13) datado por LOE, chegaríamos a 30.820 anos.

\begin{tabular}{|c|c|c|c|c|c|c|c|c|}
\hline$\frac{\tilde{E}}{\tilde{E}}$ & $\frac{0}{2}$ & 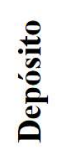 & Th & $\mathbf{U}$ & $\mathbf{K}$ & $\begin{array}{c}\text { Dosc } \\
\text { Anual }\end{array}$ & $\begin{array}{c}\text { Dosc } \\
\text { Equivalente }\end{array}$ & Idade \\
\hline & & & (ppm) & (ppm) & $(\%)$ & $\begin{array}{c}\text { ( } \mu \mathrm{Gy} / \\
\text { ano) }\end{array}$ & (Gy) & (anos) \\
\hline 01 & Congonhas & PI & $\begin{array}{c}14,609 \pm \\
0,526\end{array}$ & $\begin{array}{c}5,011 \pm \\
0,384\end{array}$ & $\begin{array}{c}1,040 \pm \\
0,151\end{array}$ & $\begin{array}{c}3.510 \pm \\
290\end{array}$ & 0,6 & $170 \pm 25$ \\
\hline 02 & Congonhas & N1 & $\begin{array}{c}2,769 \pm \\
0,100\end{array}$ & $\begin{array}{c}1,612 \pm \\
0,321\end{array}$ & $\begin{array}{c}0,760 \pm \\
0,110\end{array}$ & $\begin{array}{c}1.530 \pm \\
200\end{array}$ & 0,9 & $590 \pm 110$ \\
\hline 03 & Congonhas & N3 & $\begin{array}{c}30,852 \pm \\
1,111\end{array}$ & $\begin{array}{c}9,869 \pm \\
0,774\end{array}$ & $\begin{array}{c}2,627 \pm \\
0,381\end{array}$ & $\begin{array}{c}7.520 \pm \\
675\end{array}$ & 43,5 & $\begin{array}{c}5.790 \pm \\
810\end{array}$ \\
\hline 04 & Congonhas & N3 & $\begin{array}{c}59,049 \pm \\
2,126\end{array}$ & $\begin{array}{c}13,996 \pm \\
0,645\end{array}$ & $\begin{array}{c}2,179 \pm \\
0,316\end{array}$ & $\begin{array}{c}10.270 \pm \\
650\end{array}$ & 57,4 & $\begin{array}{c}5.600 \pm \\
360\end{array}$ \\
\hline 05 & Paraúna & PI & $\begin{array}{c}4,254 \pm \\
0,153\end{array}$ & $\begin{array}{c}1,822 \pm \\
0,796\end{array}$ & $\begin{array}{c}0,682 \pm \\
0,099\end{array}$ & $\begin{array}{c}1.680 \pm \\
320\end{array}$ & 0,3 & $180 \pm 40$ \\
\hline 06 & Paraúna & PI & $\begin{array}{c}2,600 \pm \\
0,311\end{array}$ & $\begin{array}{c}3,596 \pm \\
1,145\end{array}$ & $\begin{array}{c}0,931 \pm \\
0,135\end{array}$ & $\begin{array}{c}2.600 \pm \\
460\end{array}$ & 0,7 & $270 \pm 60$ \\
\hline 07 & Paraúna & N1 & $\begin{array}{c}21,231 \pm \\
0,764\end{array}$ & $\begin{array}{c}8,943 \pm \\
0,122\end{array}$ & $\begin{array}{c}1,757 \pm \\
0,255\end{array}$ & $\begin{array}{c}5.800 \pm \\
350\end{array}$ & 5,4 & $930 \pm 100$ \\
\hline 08 & Paraúna & $\mathrm{N} 2$ & $\begin{array}{c}31,879 \pm \\
1,148\end{array}$ & $\begin{array}{c}13,521 \pm \\
0,448\end{array}$ & $\begin{array}{c}2,195 \pm \\
0,318\end{array}$ & $\begin{array}{c}8.100 \pm \\
530\end{array}$ & 34,1 & $\begin{array}{c}4.200 \pm \\
480\end{array}$ \\
\hline 09 & Chiqueiro & N1 & $\begin{array}{c}6,747 \pm \\
0,243\end{array}$ & $\begin{array}{c}2,808 \pm \\
0,505\end{array}$ & $\begin{array}{c}1,074 \pm \\
0,156\end{array}$ & $\begin{array}{c}2.500 \pm \\
310\end{array}$ & 3,7 & $\begin{array}{c}1.480 \pm \\
250\end{array}$ \\
\hline 10 & Chiqueiro & N2 & $\begin{array}{c}13,326 \pm \\
0,480\end{array}$ & $\begin{array}{c}4,191 \pm \\
0,600\end{array}$ & $\begin{array}{c}1,835 \pm \\
0,266\end{array}$ & $\begin{array}{c}4.060 \pm \\
460\end{array}$ & 12,2 & $\begin{array}{c}3.000 \pm \\
490\end{array}$ \\
\hline 11 & Chiqueiro & N3 & $\begin{array}{c}14,575 \pm \\
0,525\end{array}$ & $\begin{array}{c}4,416 \pm \\
0,425\end{array}$ & $\begin{array}{c}1,097 \pm \\
0,159\end{array}$ & $\begin{array}{c}3.500 \pm \\
310\end{array}$ & 40,5 & $\begin{array}{c}11.560 \pm \\
1.610\end{array}$ \\
\hline 12 & Sepultura & N1 & $\begin{array}{c}4,229 \pm \\
0,152\end{array}$ & $\begin{array}{c}1,968 \pm \\
0,715\end{array}$ & $\begin{array}{c}0,532 \pm \\
0,077\end{array}$ & $\begin{array}{c}1.515 \pm \\
275\end{array}$ & 1,1 & $730 \pm 170$ \\
\hline 13 & Sepultura & $\mathrm{N} 2$ & $\begin{array}{c}3,028 \pm \\
0,109\end{array}$ & $\begin{array}{c}2,265 \pm \\
0,365\end{array}$ & $\begin{array}{c}0,675 \pm \\
0,098\end{array}$ & $\begin{array}{c}1.700 \pm \\
200\end{array}$ & 44,6 & $\begin{array}{c}26.350 \pm \\
4.470\end{array}$ \\
\hline
\end{tabular}

Figura 8 - Resultados da datação via LOE 
As amostras 03, 04 e 11 apresentam as idades para os depósitos N3 dos vales dos ribeirões Congonhas e Chiqueiro. A inexistência de datações para depósitos $\mathrm{N} 3$ de outros vales se deve à falta de material arenoso sobreposto às fácies de seixos, o que inviabiliza a coleta de amostras. A partir da análise das mencionadas amostras, pode-se inferir que no ribeirão Congonhas a formação do $\mathrm{N} 3$ ocorreu simultaneamente em diversos segmentos do vale, entre $5.600( \pm 360)$ e $5.790( \pm 810)$ anos. Isto indica que os eventos de sedimentação local, pelo menos desde a formação do $\mathrm{N} 3$, ocorreram de modo uniforme ao longo do vale. Além disso, verificase que a partir dos níveis deposicionais mais antigos, preservados nas vertentes, ocorreram sucessivas fases de erosão e deposição, representadas pelos encaixamentos e formações de depósitos fluviais. Pelo menos desde a formação dos níveis $\mathrm{N} 1$ nos vales estudados, ocorreu a estabilização do nível de base e a formação de níveis deposicionais embutidos ou encaixados (PI e N1).

A formação do N3 do ribeirão do Chiqueiro se iniciou há $11.560( \pm 1.610)$ anos, ou seja, trata-se de um depósito mais antigo que o do ribeirão Congonhas. Pode-se concluir que a sua dinâmica fluvial passou a seguir os ritmos dos ciclos erosivo-deposicionais controlados pelo rio Paraúna, enquanto nível de base regional, apenas a partir da fase erosiva que cessou com $\mathrm{o}$ início da formação do N2. Reforça essa hipótese o fato de que os níveis deposicionais mais antigos, em contexto de vertente, apresentam intervalos de encaixamento e número de níveis deposicionais distintos. Obviamente, é possível que a dinâmica fluvial, ou de vertentes, tenha proporcionado a mobilização completa de níveis deposicionais, que se encaixariam entre os que permanecem preservados. Ademais, torna-se difícil a interpretação da dinâmica fluvial em zonas serranas, nas quais os processos de vertente são mais intensos e tendem a remover as fácies mais finas. Também é preciso considerar a possibilidade de alguns níveis deposicionais em contexto de vertente terem sido recobertos por colúvios, como destacado por Saadi (1995), Ferreira (2002) e Cruz (2006).

Por se tratar de uma região de presença marcante de rochas quartzíticas fraturadas e falhadas, o esperado seria um controle litoestrutural mais pronunciado ao longo dos vales estudados. No entanto, todos os segmentos fluviais estudados têm como nível de base atual o rio Paraúna, estando os fundos de vale associados às áreas de afloramento das rochas do
Complexo de Gouveia (Figura 2), predominantemente granitos, gnaisses e migmatitos. Embora alguns trechos apresentem segmentos de corredeiras, em grande parte dos setores de baixo e médio curso dos canais investigados, não se observam grandes irregularidades nas calhas. As corredeiras, embora presentes em alguns segmentos, não chegam a representar importantes convexidades no perfil longitudinal.

\section{Dinâmica erosivo-deposicional e indícios de condicio- namento tectônico da dinâmica fluvial regional}

Os fundos de vale investigados são formados por depósitos fluviais caracterizados por planícies lateralmente estreitas e embutidas nos depósitos N1. Nos vales em que o N1 é o terraço mais antigo no fundo de vale, ele tende a preencher grande parte das áreas mais rebaixadas. No entanto, quando o N2 está em contexto de fundo de vale, este tende a ser lateralmente mais extenso. Nesses casos, o N1 encontra-se embutido ou encaixado em relação ao N2.

Nos vales estudados, a composição e a estrutura dos depósitos indicam que houve o predomínio da acreção lateral, com a formação de depósitos arenosos N1 e N2 nos fundos de vale. Esses depósitos, via de regra, foram formados no Holoceno, indicando a alteração da dinâmica hidrossedimentar regional, com a redução da capacidade e competência dos cursos fluviais. Os seixos e matacões presentes nas calhas, correlativos das antigas condições hidrológicas, são transportados apenas em períodos de aumento significativo da vazão. Para os níveis deposicionais mais antigos, outros autores apontam indícios de eventos de coluvionamento e de entulhamento dos vales. Saadi (1995) assinala pelo menos dois eventos de coluvionamento ocorridos no Pleistoceno Superior, os quais devem ter promovido o entulhamento dos vales com areias entremeadas por lentes de cascalho e argilas orgânicas, perfazendo uma planície meândrica. No entanto, são raros os depósitos fluviais que representam esse marco geomorfológico regional.

Considerando essas informações, pode-se supor que, ao longo do Pleistoceno, a dinâmica erosivodeposicional dos vales investigados foi marcada por eventos de incisão das calhas, seguidos por fases de coluvionamento e entulhamento dos vales. Durante o Holoceno, no entanto, as características dos depósitos, bem como as idades obtidas, indicam que houve 
a redução da intensidade da incisão dos canais, a alteração da dinâmica hidrossedimentar e a formação de depósitos menos espessos e mais restritos lateralmente. A regularização dos perfis longitudinais dos canais e a pequena incisão observada em alguns segmentos devem ter relação com o estabelecimento de um nível de base para o rio Paraúna, o que deve ter limitado a incisão em seus afluentes.

Diversos trabalhos apontam que, na passagem do Pleistoceno para o Holoceno, as mudanças climáticas influenciaram os processos erosivos e de agradação/ entulhamento de fundos de vale (Meis e Moura, 1984; Moura et. al., 1991; Queiroz-Neto, 2001; Liccardo et. al., 2003; Missura e Correa, 2007; Xavier e Coelho Neto, 2014), período em que foi formado o N3 do ribeirão do Chiqueiro (amostra $11-11.560 \pm 1.610$ anos). No entanto, a estratigrafia das fácies sedimentares analisadas não indica uma gênese condicionada por alterações no clima que pudessem promover condições favoráveis ao entulhamento desses canais. Trata-se de depósitos cuja estratigrafia indica o predomínio da acreção lateral na formação dos depósitos. $O$ atual regime fluvial, mesmo sob a maior umidade do Holoceno, conforme Barros et. al. (2011), é marcado por fluxos aparentemente sem a capacidade de produzir pacotes sedimentares muito espessos. Para que isso ocorresse, seria necessário que houvesse um forte processo de entulhamento das calhas e a sua posterior interrupção.

Nos vales em que a planície se encontra embutida ou encaixada no N1, as calhas fluviais costumam estar pavimentadas por seixos e matacões que podem oferecer resistência ao encaixamento (processo de encouraçamento). O que ocorre com as PI de alguns vales (ribeirão do Chiqueiro e córrego da Sepultura) é similar ao descrito por Santos et. al. (2009) para as planícies embutidas nos terraços do Rio das Velhas, nas quais há indícios de recobrimento dos terraços mais recentes.

O embutimento ou leve encaixamento dos níveis deposicionais mais recentes (PI, N1 e N2) encontrados no vale do ribeirão do Chiqueiro indicam que, desde a passagem do Pleistoceno para o Holoceno, não houve significativas oscilações no nível de base, ou seja, ele tem se apresentado praticamente estável. A inexistência de knickpoints no seu perfil longitudinal é um indício da inexistência de níveis de base locais que possam ser controlados pela litologia ou pela estrutura. Ao considerar o escalonamento do terraço mais antigo em fundo de vale, em relação aos níveis deposicionais em contexto de vertente, pode-se inferir que ao longo do Pleistoceno a atividade neotectônica foi mais intensa do que no Holoceno, pelo menos para o ribeirão do Chiqueiro. Portanto, a formação de depósitos embutidos no fundo do vale parece estar associada tanto à estabilização do nível de base regional (rio Paraúna), como pelo encouraçamento da calha fluvial (Messias e Magalhães Jr, 2014) decorrente da remobilização dos clastos de depósitos mais antigos. Devido às características faciológicas dos depósitos, bem como morfológicas dos demais vales, é possível considerar que o embutimento ou leve encaixamento das planícies nos N1, resultam da estabilização do nível de base regional e, em alguns trechos, do encouraçamento das calhas.

Ao observar as idades obtidas para os depósitos formados por eventos que foram sucedidos por fases de encaixamento da drenagem, como se observa nos vales do rio Paraúna, ribeirão Congonhas e córrego da Sepultura, pode-se inferir que desde o Pleistoceno Superior e, principalmente, durante o Holoceno, a Serra do Espinhaço Meridional sofreu alterações no nível de base regional. Essa proposição está de acordo com o que afirma Saadi (1995), que relata a existência de quatro terraços escalonados e um nível de planície no Quadrilátero Ferrífero, decorrentes do soerguimento quaternário da Serra, e com Bueno et. al. (1997), que associam os ciclos deposicionais e de maior dissecação ao contexto de instabilidade tectônica na bacia do ribeirão do Chiqueiro. A neotectônica regional parece ocorrer sob forma de longos períodos de estabilidade tectônica intraplaca interrompidos por espasmos tectônicos mais intensos, os quais estão sendo cada vez mais frequentes desde o Mesozoico (Valadão, 2009).

Entre os argumentos que podem sustentar a hipótese de reativação neotectônica estão os ciclos erosivo-deposicionais ocorridos nos vales citados. No córrego da Sepultura, o tempo decorrido entre a formação do N2 (26.350 4.470 anos) e a formação do N1 (730 \pm 170 anos), foi marcado pelo rebaixamento do talvegue em cerca de 3 metros. Isto indica que ao longo do final do Pleistoceno Superior e durante grande parte do Holoceno, o córrego da Sepultura apresentou uma dinâmica fluvial distinta daquela nos demais vales investigados, porém caracterizada pelo rebaixamento do nível de base. No rio Paraúna, a última fase de 
encaixamento da drenagem ocorreu entre a formação do N2 (4.200 \pm 480 anos) e a deposição do N1 (930 \pm 100 anos). Nesse caso, pode-se inferir que, ao longo do Holoceno ocorreram alterações no nível de base que culminaram no encaixamento da drenagem. Já no ribeirão Congonhas, o período compreendido entre a deposição do N3 (5.790 \pm 810 anos) e a do N1 (590 \pm 110 anos) foi marcado pelo encaixamento da drenagem em 15 metros, sendo 10 metros entre o N3 e o N2 e de 5 metros entre o N2 e o N1. Além disso, em todos os vales investigados são observados níveis deposicionais escalonados, o que corrobora com a hipótese de reativações neotectônicas que atingiram toda ou grande parte da Serra do Espinhaço Meridional, mesmo que isso tenha ocorrido com intensidades locais diferentes, registradas por taxas de encaixamento distintas.

\section{Considerações finais}

No Sudeste do Brasil, a reconhecida atividade neotectônica parece estar influenciando a dinâmica erosivo-deposicional de cursos fluviais em diferentes contextos geológico-geomorfológicos. Como resultado dessa influência, ocorrem alterações na forma como se organizam espacialmente essas redes de drenagem e a promoção da individualização de domínios morfológicos. A distribuição espacial de terraços fluviais na Serra do Espinhaço Meridional, bem como a sua localização transversal em cada vale parece refletir uma dinâmica neotectônica marcada por pulsos temporais de blocos que interrompem longos períodos de maior estabilidade do Escudo Brasileiro. Enquanto a formação dos depósitos de fundo de vale sugere o estabelecimento de um nível de base regional, a disposição dos níveis deposicionais em contexto de vertente indicam constantes alterações dos níveis de base locais, que podem ser reflexo de uma dinâmica de blocos alimentada pelas movimentações neotectônicas ocorridas no Pleistoceno e no início e meio do Holoceno.

Ao longo do Pleistoceno, a Serra do Espinhaço Meridional foi marcada por uma alternância de fases de encaixamento da drenagem e de eventos de coluvionamento, acompanhados pela colmatação dos fundos de vale. No Holoceno, porém, parece ter ocorrido a redução da intensidade dos pulsos neotectônicos, o estabelecimento de um nível de base regional representado pelo rio Paraúna e o predomínio de dinâmicas hidrossedimentares que têm proporcionado a redução da capacidade e competência dos cursos fluviais. Estes processos foram acompanhados da formação de níveis deposicionais embutidos ou levemente encaixados em relação aos mais antigos localizados nos fundos de vale. Com relação à dinâmica fluvial atual, embora se observe a estabilização de um nível de base regional, representado pelo rio Paraúna, isso pode não representar a cessação dos movimentos positivos decorrentes da neotectônica. A Serra do Espinhaço Meridional está sujeita aos movimentos positivos do Escudo Brasileiro, enquanto os movimentos diferenciais de blocos regionais e locais parecem vir atenuando-se ao longo do Quaternário. Ao mesmo tempo, pode-se supor que o rio Paraúna não tem conseguido romper seu nível de base, representado pelo desnível em seu trecho de baixo curso, próximo da confluência com o rio Cipó e o Rio das Velhas.

Quanto à utilização da datação de sedimentos fluviais via LOE, esta permitiu a construção de hipóteses e reflexões sobre a dinâmica fluvial quaternária, sobretudo acerca das fases de incisão da rede de drenagem e das fases de sedimentação. Desse modo, foi possível propor com maior precisão a idade de eventos regionais e locais de sedimentação e de incisão dos canais, bem como associar esses eventos à possível dinâmica neotectônica.

\section{Referências bibliográficas}

ALMEIDA-ABREU, P. A.; RENGER, F. E. Serra do Espinhaço Meridional: um orógeno de colisão do Mesoproterozóico. Revista Brasileira de Geociências, São Paulo, v. 32, n. 1, p. $1-14,2002$

BARROS, L. F. P.; LAVARINI, C.; LIMA, L. S.; MAGALHÃES JÚNIOR, A. P. Síntese dos cenários paleobioclimáticos do Quaternário tardio em Minas Gerais/Sudeste do Brasil. Uberlândia: Revista Sociedade e Natureza. v. 23, n. 3, p. 371386, 2011.

BENITES, V. M.; CAIAFA, A. N.; MENDONÇA, E. S.; SCHAEFER, C. E.; KER, J. C. Solos e vegetação nos complexos rupestres de altitude da Mantiqueira e do Espinhaço. Floresta e Ambiente, v. 10, p. 76-85, 2003.

BENITES, V. M.; SCHAEFER, C. E. G. R.; SIMAS, F. N. B.; SANTOS, H. G. Soils associated with rock outcrops in the Brazilian mountain ranges Mantiqueira and Espinhaço. Revista

Brasileira de Botânica, v. 30, p. 569-577, 2007. 
BUENO, G. T.; TRINDADE, E. S.; MAGALHÃES JUNIOR, A. P. Paleociclos deposicionais e a moderna dinâmica fluvial do ribeirão do Chiqueiro - Depressão de Gouveia/Espinhaço Meridional - MG. Geonomos, v. 5, n. 2, p. 15-19, 1997.

CHRISTOFOLETTI, A. Geomorfologia fluvial. São Paulo: Edgar Blücher, 1981, 313p.

CORRÊA, A. C. B.; SILVA, D. G.; MELLO, J. S. Utilização dos depósitos de encostas dos brejos pernambucanos como marcadores paleoclimáticos do Quaternário Tardio no semiárido nordestino. Mercator, v. 7, p. 99-125, 2008.

CRUZ, L. O. M. Assinatura geoquímica de unidades coluviais da Bacia do Córrego do rio Grande - Depressão de Gouveia/ MG. Dissertação de Mestrado. Instituto de Geociências, Universidade Federal de Minas Gerais, Belo Horizonte, 2006, $137 \mathrm{p}$.

FERREIRA, A. O. Mapeamento das formações superficiais da bacia do Córrego do Rio Grande - Depressão de Gouveia (Serra do Espinhaço Meridional/MG). Dissertação de Mestrado. Belo Horizonte: IGC/UFMG, 2002, 138p.

FOGAÇA, A. C. C. Geologia da Folha Diamantina. In GROSSISAD, J. H.; LOBATO, L. M.; PEDROSA-SOARES, A. C.; SOARES-FILHO, B. S. (coordenadores e editores). PROJETO ESPINHAÇO EM CD-ROM (textos, mapas e anexos). Belo Horizonte, COMIG - Companhia Mineradora de Minas Gerais. p. $1575-1665,1997$.

HORÁK, I., VIDAL-TORRADO, P., SILVA, A.C., PESSENDA, L. C. R. Pedological and isotopic relations of a highland tropical peatland, Mountain Range of the Espinhaço Meridional (Brazil). Revista Brasileira de Ciência do Solo, v. 35, p. 41-52, 2011.

KING, L. A geomorfologia do Brasil oriental. Revista Brasileira de Geografia, v. 18, n. 2, p.147-265, 1956.

KNAUER, L. G. O Supergrupo Espinhaço em Minas Gerais: considerações sobre sua estratigrafia e seu arranjo estrutural. Geonomos, v. 15, p. 81-90, 2007.

KNAUER, L. G.; GROSSI-SAD, J. H.. Geologia da Folha Presidente Kubitschek. In: GROSSI-SAD, J. H.; LOBATO, L. M.; PEDROSA-SOARES, A. C.; SOARES-FILHO, B. S. (coordenadores e editores). PROJETO ESPINHAÇO EM CD-ROM (textos, mapas e anexos). Belo Horizonte, COMIG Companhia Mineradora de Minas Gerais. p. 1901-2055, 1997.

LICCARDO, A.; ADDAD, J. E.; SIMÕES, L. Depósitos secundários quaternários de Coríndon em Minas Gerais. In: IX Congresso da Associação Brasileira de Estudos Quaternários, 9, Recife. II Congresso do Quaternário de Países de Língua Ibérica e II Congresso sobre Planejamento e Gestão da Zona Costeira dos Países de Expressão Portuguesa. Anais do IX Congresso... Recife: ABEQUA, 2003.

MEIS, M. R. M.; MOURA, J. R.. Upper Quaternary sedimentations and hillslope evolution. Am. Journal Science. v. 284, p. 241- 254, 1984.

MESSIAS, R. M.; MAGALHÃES JUNIOR, A. P. Níveis deposicionais aluviais no vale do córrego do Rio Grande, Depressão de Gouveia - MG. In: $10^{\circ}$ Simpósio Nacional de Geomorfologia, Manaus, 2014. Anais do $\mathbf{1 0}^{\circ}$ Simpósio... Manaus, 2014.

MISSURA, R.; CORREA, A. C. B. Evidências Geomorfológicas como Ferramentas para a Reconstrução Paleogeográfica na Mantiqueira Ocidental- MG. Revista de Geografia (Recife), v. 24, p. 262-278, 2007.

MOURA, J. R. S.; PEIXOTO, M. N. O.; SILVA, T. M. Geometria do relevo e estratigrafia do quaternário como base à tipologia de cabeceiras de drenagem em anfiteatro - médio vale do Rio Paraíba do sul. Revista Brasileira de Geociências. v. 21, n. 3, p. 255-265, 1991.

PEREIRA, M. G.; ANJOS, L. H. C. \& VALLADARES, G. S. Organossolos: Ocorrência, gênese, classificação, alterações pelo uso agrícola e manejo. In: VIDAL-TORRADO, P.; ALLEONI, L. R. F.; COOPER, M.; SILVA, A.P. \& CARDOSO, E. J., eds. Tópicos em ciência do solo. Viçosa, MG. Sociedade Brasileira de Ciência do Solo, v. 4, p. 233-276, 2005.

PEREZ-FILHO, A.; QUARESMA, C. C.; ESPINDOLA, C. R.; RODRIGUES, T. R. I. Geomorfologia antropogênica: reativação da rede de drenagem e processos erosivos relacionados à construção civil. In: VI Simpósio Nacional de Geomorfologia, 6. Anais do VI... Goiânia, 2006.

PONTEVEDRA-POMBAL, X.; MARTINEZ-CORTIZAS, A. Tuberas de Galicia: Processos formativos, distribuición y valor medioambiental. El caso particular de lãs "Serras Septentrionais”. Chioglossa, v. 2:103-121, 2004.

QUEIROZ NETO, J. P. O estudo de formações superficiais no Brasil. São Paulo: Revista do Instituto Geológico, v. 22, n. 2, 65-78, 2001.

SAADI, A. A geomorfologia da Serra do Espinhaço em Minas Gerais e de suas margens. Geonomos, v. 3, n. 1, p. 41-63, 1995.

SAADI, A. Ensaio Sobre a Morfotectônica de Minas Gerais tensões intra-placa, descontinuidades crustais e morfogênese. Tese de Professor Titular. Belo Horizonte: UFMG, IGC, 1991, $285 \mathrm{p}$. 
SAllun, A. E. M., SUGUIO, K.; TATUMI, S. H.; YEE, M.; SANTOS, J.; BARRETO, A. M. F.. Datação absoluta de depósitos quaternários brasileiros por luminescência. Revista Brasileira de Geociências, v. 37, n. 2, p. 401-412, 2007.

SALlUN, A. E. M.; SUGUIO, K.; Depósitos quaternários da região entre Marília e Presidente Prudente (SP). Revista Brasileira de Geociências, v. 36, n. 3, p. 385-395, 2006.

SANTOS, G. B.; MAGALHÃES JUNIOR, A. P.; CHEREM, L. F. S. Níveis de terraços fluviais e depósitos sedimentares correlativos no alto vale do rio das Velhas, quadrilátero ferrífero, MG. Revista Brasileira de Geomorfologia, v. 10, n. 1, P. 7384, 2009.

SILVA, E. de B., SILVA, A. C., GRAZZIOTTI, P. H., FARNEZI, M. M. de M., FERREIRA, C. A., COSTA, H. A. O., HORAK, I. Comparação de métodos para estimar a acidez potencial mediante determinação do pH SMP em organossolos da Serra do Espinhaço Meridional. Revista Brasileira de Ciência do
Solo, v. 32, p. 2007-2013, 2008.

TURCQ, B.; SUGUIO, K; SOUBIES, F.; SERVANT, M.; PRESSINOT, M. M. N. Alguns terraços fluviais do sudeste e centro-oeste brasileiro datados por radiocarbono: possíveis significados paleoclimáticos. In: Congresso da Abequa, I, Porto Alegre, 1987. Anais... Abequa; UFRGS, p. 379-392, 1987.

VALADÃO, R. C. Geodinâmica de superfícies de aplanamento, desnudação continental e tectônica ativa como condicionantes da megageomorfologia do Brasil Oriental. Revista Brasileira de Geomorfologia, v. 10, n. 2, p. 77-90, 2009.

WALLINGA, J. Optically stimulated luminescence dating in fluvial deposits: a review. Boreas, v. 31, p. 303-322, 2002.

XAVIER, R. A.; COELHO NETTO, A. L. Caracterização geomorfológica da bacia do Rio Turvo-RJ: Médio Vale do Rio Paraíba do Sul (MVPRS). Revista Brasileira de Geomorfologia. v. 15, n 1. 2014. 